\title{
Air-stable and efficient inorganic-organic heterojunction solar cells using PbS colloidal quantum dots co-capped by 1-dodecanethiol and oleic acid
}

\author{
Sungwoo Kim ${ }^{\dagger a, b}$, Sang Hyuk Im ${ }^{\dagger a}$, Meejae Kang ${ }^{b}$, Jin Hyuck Heo ${ }^{a}$, Sang Il Seok ${ }^{a}$, Sang-Wook Kim* ${ }^{b}$, \\ ${ }_{5}$ Iván Mora- Seró, $^{\mathrm{c} *}$ and Juan Bisquert ${ }^{\mathrm{c}}$
}

\author{
Received (in $X X X, X X X$ ) Xth $X X X X X X X X X 200 X$, Accepted Xth $X X X X X X X X X 200 X$ \\ First published on the web $X$ th $X X X X X X X X X 200 X$ \\ DOI: $10.1039 / b 000000 x$
}

\begin{abstract}
${ }_{10} \mathrm{PbS}$ colloidal quantum dot (CQD)-sensitized inorganic-organic heterojuction solar cells fabricated by using the PbS CQDs cocapped by the oleic acid (OA) and 1-dodecanethiol (DT) ligand showed better device stability with aging time under ambient conditions without encapsulation. Furthermore, the device 15 performance is better than the cell fabricated from PbS CQDs without DT ligand. The enhancement of performance in $\mathrm{OA}$ and DT co-capped systems is investigated by impedance spectroscopy. An upwards displacement of the $\mathrm{TiO}_{2}$ conduction band, with a consequent increase of $\mathrm{V}_{\mathrm{oc}}$, originate the improved performance 20 when CQD with DT are employed.
\end{abstract}

Recently, solar energy conversion devices have been of great interest because solar energy is green, renewable, and sustainable. In particular, since Grätzel et al. reported the development of highly efficient dye-sensitized solar cells (D${ }_{25}$ SSCs), ${ }^{1}$ SSCs have been extensively studied to replace conventional solar cells because they are transparent and costeffective. However, the weak absorption of conventional $\mathrm{Ru}$ dyes requires a thick mesoscopic $\mathrm{TiO}_{2}$ electrode of $\sim 10 \mu \mathrm{m}$, and the liquid redox electrolyte has the potential to leak.

${ }_{30}$ These issues seem to pose a problem in finding further applications for conventional D-SSCs, such as flexible solar cells, because bending can cause the thick $\mathrm{TiO}_{2}$ electrode to break and the liquid electrolyte to leak. Therefore, it is desirable to use a new sensitizer with a strong absorption 35 coefficient and a solid hole transporting material instead of liquid electrolyte. From this viewpoint, it is beneficial to develop efficient solid-state inorganic semiconductor- or quantum dot-sensitized solar cells (QD-SSCs) because they have a higher absorption coefficient than conventional 40 $\mathrm{Ru}$ /organic dyes, convenient bandgap tunability by size control, easier charge separation because of a large intrinsic dipole moment, and multiple exciton generation. ${ }^{2}$ Unlike $p-n$ heterojunction solar cells, sensitized solar cells are constructed using three key components: an electron 45 conductor, a sensitizer, and a hole conductor. This unique feature enables SSCs to attain a high energy conversion efficiency because the electron-hole pairs generated in the sensitizer are quickly separated into the electron conductor and hole conductor, which suppresses the recombination of 50 the generated charge carriers. Accordingly, SSCs based on a metal chalcogenide such as $\mathrm{CdS}(\mathrm{e}),{ }^{3} \mathrm{PbS},{ }^{4}$ or $\mathrm{Sb}_{2} \mathrm{~S}_{3}{ }^{5}$ have been intensively studied.

Among the metal chalcogenides, $\mathrm{PbS}$ colloidal quantum dots (CQDs) have attracted great attention because their 5 bandgap to a large extent can be controlled by the quantum confinement effect as a result of their narrow bulk energy bandgap $(0.41 \mathrm{eV})$ and small exciton Bohr radius $(18 \mathrm{~nm}){ }^{6}$ Sargent et al. ${ }^{7}$ developed efficient PbS CQD Schottky and $n-p$ heterojunction solar cells. We have also fabricated PbS CQD60 sensitized solar cells. ${ }^{4}$ The main factors for the successful demonstration of efficient solar cells are an optimized device architecture and improved interfacial contact between the $\mathrm{PbS}$ CQDs. Device optimization has been used to extend the interfacial area of the n-type electron conductor and p-type ${ }_{65} \mathrm{PbS} \mathrm{CQD}$ in order to improve the charge transport. However, the performance of $\mathrm{PbS} \mathrm{CQD}$-based solar cells tends to quickly degrade upon exposure to air because of the oxidation of the $\mathrm{PbS}$ CQDs. Therefore, it is equally important to improve device stability in order to aid commercial 70 application. Very recently, atomic passivation of PbS CQDs ${ }^{7 \mathrm{a}}$ and introduction of a $\mathrm{LiF}$ interlayer ${ }^{7 \mathrm{~b}}$ between $\mathrm{PbS}$ CQDs and counter metal electrode have been proposed to improve the air stability of operating devices. In an effort to improve the air stability of PbS CQDs, in this study we used dodecanethiol as 75 an organic passivator during the colloidal synthesis of $\mathrm{PbS}$ CQDs and applied them to PbS CQD-SSCs to improve device stability.
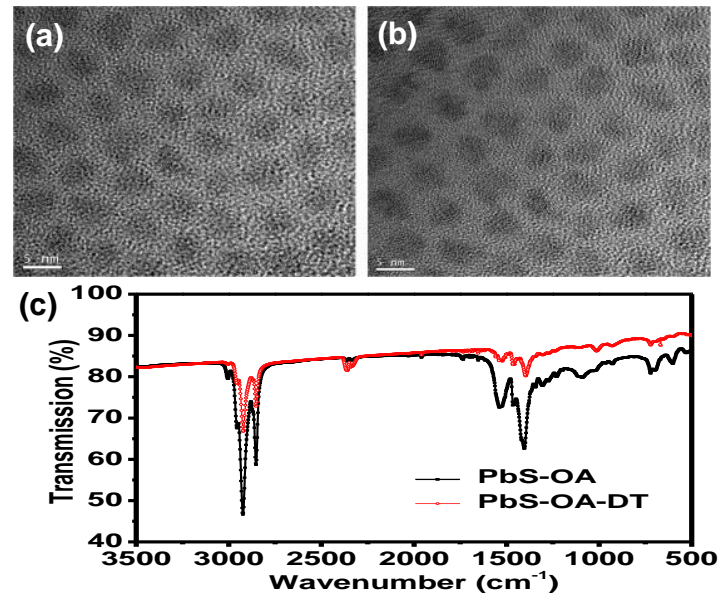

Fig. 1. TEM images of synthesized (a) PbS-OA and (b) PbS-OA-DT CQDs; and (c) their FT-IR spectra. 
Fig. 1(a) and (b) show transmission electron microscopy (TEM) images of the synthesized PbS-OA and PbS-OA-DT CQDs. These images indicate that the average sizes of both CQDs are almost the same $(4.5 \mathrm{~nm})$. Therefore, their 5 absorption peaks are located at the same wavelength, $\sim 1150$ $\mathrm{nm}$. The slight difference in the apparent morphologies can be attributed to the strong selective bonding of DT molecules onto the $\{111\}$ faces of $\mathrm{PbS}$ nanocrystals, which alters the shape of the growing PbS nanocrystals. ${ }^{8}$ The FT-IR spectra of 10 the PbS-OA and PbS-OA-DT CQDs are shown in Fig. 1(c). The symmetric and antisymmetric $\mathrm{C}-\mathrm{H}$ stretching vibrations and $=\mathrm{C}-\mathrm{H}$ stretching vibration at 2850, 2920, and $3006 \mathrm{~cm}^{-1}$, respectively, indicate the presence of $\mathrm{OA}$ on the $\mathrm{PbS}$ CQDs. ${ }^{9}$ The disappearance of the $\mathrm{C}=\mathrm{O}$ stretching vibration at 1710 $15 \mathrm{~cm}^{-1}$ in $\mathrm{OA}$ and the new peak for $\mathrm{Pb}$-oleate at $1544 \mathrm{~cm}^{-1}$ confirm the formation of a chemical bond between $\mathrm{PbS}$ and OA. ${ }^{9}$ The C-S vibration of DT at $1384 \mathrm{~cm}^{-1}$ indicates the cocapping of DT molecules on the PbS CQDs, and the missing S-H stretching peak for DT at $2567 \mathrm{~cm}^{-1}$ implies the formation 20 of a chemical bond between PbS and DT. ${ }^{9}$


Fig. 2. Visible-NIR absorption spectra of PbS-OA (a) and PbS-OADT (b) CQDs with and without accelerated aging at $120{ }^{\circ} \mathrm{C}$ for $6 \mathrm{~h}$ in convection oven; and high resolution XPS S 2 p spectra of PbS-OA (c) and PbS-OA-DT (d) $\left(-\mathrm{R}=\right.$ room temperature, $-\mathrm{H}=$ aged at $120^{\circ} \mathrm{C}$ 25 for $6 \mathrm{~h})$.

To determine whether the strong bond of DT molecules with $\mathrm{PbS}$ CQDs can improve the air stability of the device, we stored the PbS-OA and PbS-OA-DT CQDs in chloroform 30 solutions at room temperature (-R) and $120{ }^{\circ} \mathrm{C}$ in a convection oven $(-\mathrm{H})$, respectively, for $6 \mathrm{~h}$. When the PbS CQD solutions were placed in the convection oven at $120{ }^{\circ} \mathrm{C}$, the chloroform solvent quickly evaporated, and the $\mathrm{PbS}$ CQDs were exposed to air for a certain time period. As shown in Fig. 2(a) and (b), 35 the visible- near-infrared (vis-NIR) absorption spectrum of the $\mathrm{PbS}-\mathrm{OA}-\mathrm{A}$ CQDs annealed at $120^{\circ} \mathrm{C}$ for $6 \mathrm{~h}$ is different from that of the PbS-OA-R CQDs. The blue shift observed in the absorption spectrum during the heat stability test indicates the oxidation of the PbS-OA CQDs. On the other hand, the PbS${ }_{40}$ OA-DT CQDs did not reveal any change in the absorption spectrum after the stability test. To understand what happened during the stability test, we compared the X-ray photoelectron spectroscopy (XPS) spectra, as shown in Fig. 2(c) and (d). From the $\mathrm{S} 2 \mathrm{p}$ and $\mathrm{Pb} 4 \mathrm{f}$ high-resolution XPS peak analyses, ${ }^{7 \mathrm{c}}$ 45 we can see that the PbS-OA CODs were more severely oxidized to $\mathrm{PbSO}_{4}$ or $\mathrm{PbSO}_{3}$ during the aging test while the PbS-OA-DT CQDs were only slightly degraded. Here, it should be noted that the co-capped DT molecules provided air stability even for relatively large PbS CQDs, whereas only the 50 small PbS-OA CQDs showed air stability because the relatively large $\mathrm{PbS}-\mathrm{OA} \mathrm{CQDs}$ had unpassivated $\mathrm{S}$ atoms exposed on the surface of the PbS CQDs, which were likely to be oxidized during the aging test. ${ }^{7 \mathrm{c}}$ The improvement in the air stability of the PbS CQDs by the co-capped DT molecules 55 might be attributed to the fact that the PbS-OA-DT CQDs had $S$ atoms passivated by the long alkyl chain of DT on the surface, whereas the PbS-OA CQDs had unpassivated S atoms. The improvement in the air stability of the PbS CQDs by simply using co-capped DT molecules enables us to exploit ${ }_{60}$ light with longer wavelength more stably in the fabrication of photovoltaic devices.

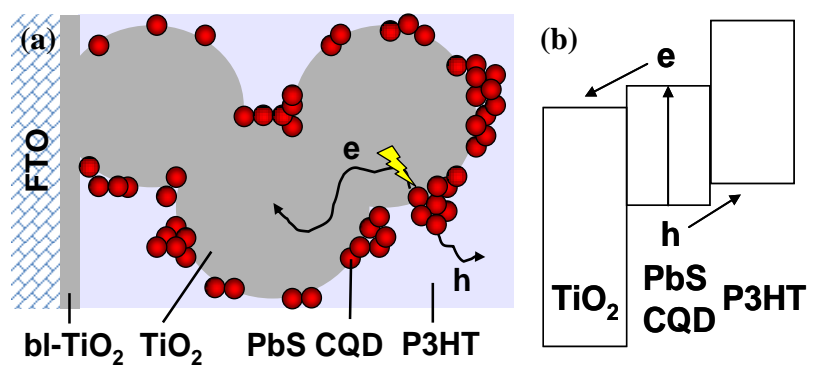

Fig. 3. (a) Schematic of PbS CQD-SSC and (b) its energy band diagram.

65 On the basis of the fact that co-capped DT molecules can improve the air stability of $\mathrm{PbS}$ CQDs, we fabricated $\mathrm{PbS}$ CQD-SSCs ${ }^{4 \mathrm{~b}}$ to determine whether the PbS-OA-DT CQDs can also improve the device stability. Fig. 3 shows a schematic of the device and its band energy diagram. Under the 70 illumination of light, the $\mathrm{PbS}$ CQD sensitizer absorbs the light and generates electron-hole pairs. The generated electrons (holes) are then transferred into the $\mathrm{TiO}_{2}$ electron conductor (P3HT hole conductor). Typically, PbS CQDs-SSCs are fabricated by multiple spin-casting of a PbS CQD solution on 75 an $\mathrm{mp}-\mathrm{TiO}_{2}$ film using EDT linker molecules and by postEDT treatment to improve the interfacial contact between $\mathrm{PbS}$ CQDs. ${ }^{4 \mathrm{~b}}$ The representative EQE spectrum and photocurrent density-voltage (J-V) curve of the PbS-OA-DT CQD-SSC are shown in Fig. 4.
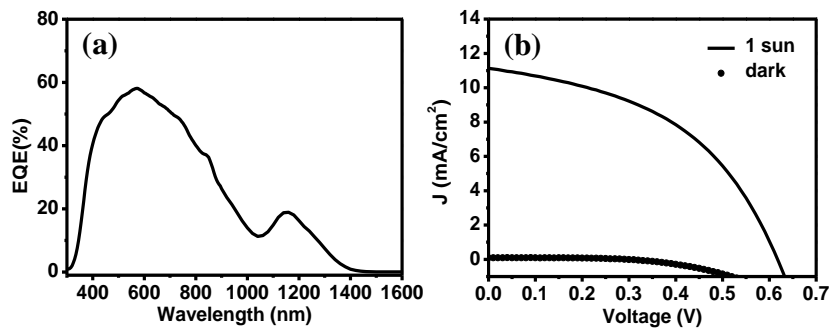

80 Fig. 4. (a) EQE spectrum and (b) J-V curve of PbS-OA-DT CQDSSC. 
The EQE spectrum indicates that the light (from the visible to NIR region) absorbed by the $\mathrm{PbS}$ CQDs is efficiently converted into electricity by this SSC, and the EQE value at $1150 \mathrm{~nm}$ reaches $\sim 20 \%$. This implies that this PbS CQD-SSC 5 can be used to detect light in the NIR region. The PbS-OA-DT CQD-SSC exhibited a short circuit current density $\left(\mathrm{J}_{\mathrm{sc}}\right)$ of 11 $\mathrm{mA} / \mathrm{cm}^{2}$, an open circuit voltage $\left(\mathrm{V}_{\mathrm{oc}}\right)$ of $0.61 \mathrm{~V}$, and a fill factor (FF) of $50.4 \%$. Accordingly, it showed an overall power conversion efficiency $(\eta)$ of $3.3 \%$ at 1 sun $\left(100 \mathrm{~mW} / \mathrm{cm}^{2}\right.$ AM $101.5 \mathrm{G})$ illumination.

Table 1. Summary of initial device performances of $\mathrm{PbS}-\mathrm{OA}$ and $\mathrm{PbS}$ OA-DT CQD-SSCs.

\begin{tabular}{|c|c|c|c|c|}
\hline & $\mathrm{J}_{\mathrm{sc}}\left(\mathrm{mA} / \mathrm{cm}^{2}\right)$ & $\mathrm{V}_{\mathrm{oc}}(\mathrm{V})$ & $\mathrm{F} . \mathrm{F}(\%)$ & $\eta(\%)^{\mathrm{a}}$ \\
\hline $\mathrm{PbS}-\mathrm{OA}$ & 11.5 & 0.46 & 47.2 & 2.5 \\
\hline $\mathrm{PbS}-\mathrm{OA}-\mathrm{DT}$ & 11.0 & 0.61 & 50.4 & 3.3 \\
\hline
\end{tabular}

${ }^{a}$ : Unencapsulated devices were measured under 1 sun condition in air atmosphere.
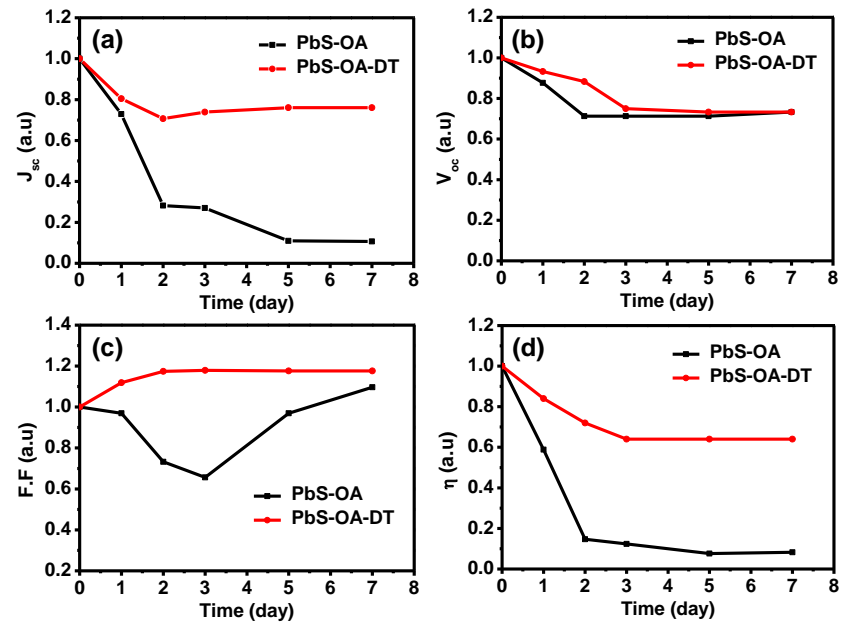

15 Fig. 5 Air stability of PbS CQD-SSCs with aging time under ambient conditions. (a) Short circuit current density $\left(\mathrm{J}_{\mathrm{sc}}\right)$, (b) open circuit voltage $\left(\mathrm{V}_{\mathrm{oc}}\right)$, (c) fill factor $(\mathrm{FF})$, and (d) power conversion efficiency ( ).

20 To compare the air stability of the PbS-OA and PbS-OADT CQD-SSCs, we fabricated two devices using the same fabrication procedure and measured their I-V characteristics at 1 sun illumination. Here, we did not encapsulate the devices but stored them under ambient conditions. The changes in $\mathrm{J}_{\mathrm{sc}}$, ${ }_{25} \mathrm{~V}_{\text {oc }}, \mathrm{FF}$, and $\eta$ of the PbS-OA and PbS-OA-DT CQD-SSCs with time are shown in Fig. 5. The initial performance of each device is summarized in Table 1 . This clearly indicates that the co-capped DT molecules on the PbS CQD surface can also improve the air stability of an SSC. The improved air stability

30 of the PbS CQD-SSC was resulted in the improved $\mathrm{J}_{\mathrm{sc}}$ in the cell, because the oxidation layer on the PbS CQDs hinders the charge transfer/transport between $\mathrm{PbS}$ CQDs. A degradation of $\mathrm{ca} .30 \%$ in the power conversion efficiency of the PbS-OADT CQD-SSC might be associated with the intrinsically 35 uncapped S atoms, because DT molecules will be bound to the $\mathrm{Pb}$ atoms on the surface of the PbS CQDs. The EDT treatment may also cause the PbS CQDs to be oxidized by air because the short EDT linker molecules can quickly replace the longer

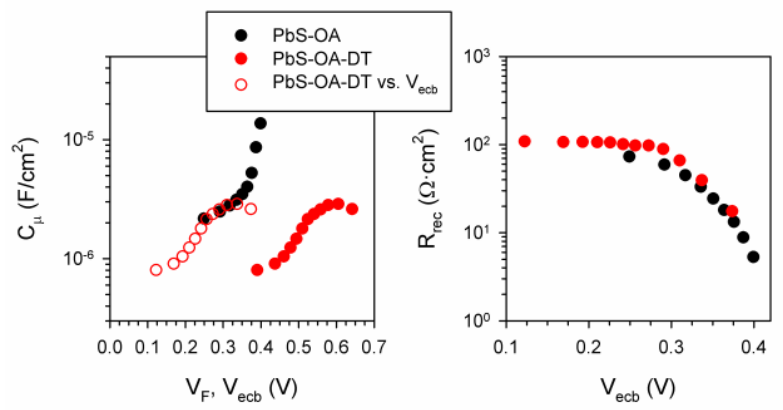

OA capping ligand and, thus, may reduce the air stability.

40 Fig. 6 (a) Chemical Capacitance $\left(\mathrm{C}_{\mu}\right)$, and (b) recombination resistance $\left(\mathrm{R}_{\mathrm{rec}}\right)$ obtained from impedance analysis under 1 sun illumination.

To further confirm the role of DT co-capped in PbS CQDs, 45 we compared the impedance spectroscopy (IS) measurements of each device under the working conditions at 1 sun illumination in applying bias voltage, $\mathrm{V}_{\text {app }}$, of $100-700 \mathrm{mV}$, as shown in Fig. 6. Nyquist plot of the analyzed samples present two semicircles assigned, the one at higher frequency, to 50 transport along hole conducting media, and to the charge transfer at $\mathrm{TiO}_{2} / \mathrm{PbS} / \mathrm{P} 3 \mathrm{HT}$ interface, at lower frequencies. ${ }^{10}$ From the second semicircle, it is possible to obtain the chemical capacitance $\left(\mathrm{C}_{\mu}\right)$ of $\mathrm{TiO}_{2}$, ef-Fig. 6(a), and the recombination resistance $\left(\mathrm{R}_{\mathrm{rec}}\right)$ at the interface, of-Fig. 6(b).

${ }_{55}$ Chemical capacitance is represented vs. $V_{F}$, the voltage drop at the active electrode, simply but subtracting to $\mathrm{V}_{\text {app }}$ the voltage drop at the series resistance. ${ }^{11} \mathrm{C}_{\mu}$ shows a significant shift of the chemical capacitance between samples with and without DT, indicating an upwards displacement of the $\mathrm{TiO}_{2}$ 60 conduction band (CB). This displacement can be removed shifting the capacitance and overlapping the capacitances of both samples, Fig. 6(a). In this case the capacitances are represented against a common equivalent conduction band position, $\mathrm{V}_{\mathrm{ecb}}{ }^{11,12}$ Note that the recombination resistance is ${ }_{65}$ dependent of the $\mathrm{CB}$ position as it depends on the electron density. $R_{\text {rec }}$ does not present any significant change when the CB shift is removed, Fig. 6(b). In this sense, the main effect of DT is an upwards shift of $\mathrm{TiO}_{2}$. This shift enhances the $\mathrm{V}_{\mathrm{oc}}$ obtained for PbS-OA-DT, see Table 1. Probably DT are 70 working as surface dipoles influencing the $\mathrm{TiO}_{2} \mathrm{CB}$ position as it has been previously reported. ${ }^{12}$ Currently it is under study if DT also affect the position of energy levels in $\mathrm{PbS}$ CQDs. Thus DT plays a double beneficial role: i) shifting up $\mathrm{TiO}_{2} \mathrm{CB}$, and consequently enhancing the cell $\mathrm{V}_{\mathrm{oc}}$ and 75 conversion efficiency; and ii) passivating CQDs surface increasing the device stability.

In summary, we designed and synthesized PbS CQDs via solution chemistry using OA and DT capping molecules to improve the air stability. The PbS CQDs capped by OA and ${ }_{80}$ DT molecules (PbS-OA-DT) exhibited much better air stability than the PbS CQDs capped only by OA molecules ( $\mathrm{PbS}-\mathrm{OA})$ during the accelerated aging test, because the $\mathrm{PbS}$ - 
OA-DT CQDs had their S atoms passivated by the long alkyl chain of the DT ligand on their surface whereas the PbS-OA CQDs did not have any passivated $\mathrm{S}$ atoms on the surface. In addition, PbS-OA-DT coating produces an upwards 5 displacement of $\mathrm{TiO}_{2}$ conduction band enhancing consequently the $\mathrm{V}_{\mathrm{oc}}$. When we applied the PbS-OA-DT CQDs to SSC, we could obtain a power conversion efficiency of $3.3 \%$ at 1 sun illumination. The PbS-OA-DT CQD-SSC also exhibited better device stability with aging time under 10 ambient conditions than the PbS-OA CQD-SSC.

\section{Acknowledgements}

This work was supported by the Global Research Laboratory (GRL) Program, the Global Frontier R\&D Program on Center for Multiscale Energy System, and the Priority Research ${ }_{15}$ Centers Program (2009-0093826) funded by the National Research Foundation in Korea, and by a grant from the KRICT 2020 Program for Future Technology of the Korea Research Institute of Chemical Technology (KRICT), Republic of Korea.

\section{${ }_{20}$ Notes and references}

${ }^{a}$ Division of Advanced Materials, Korea Research Institute of Chemical Technology, 141 Gajeong-Ro, Yuseong-Gu, Daejeon 305-600, Korea. Fax:+82-42-861-4251; Tel:+82-42-860-7314; E-mail: seoksi@krict.re.kr ${ }^{b}$ Department of Molecular Science and Technology, Ajou University,

25 Suwon, 443-749, Korea. Fax: +82-31-219-2394; E-mail: swkim@ajou.ac.kr

${ }^{c}$ Photovoltaic and Optoelectronic Devices Group, Departament de Física, Universitat Jaume I, 12071 Castelló, Spain, E-mail: sero@fca.uji.es

${ }^{+}$: These authors are equally contributed to this work.

30

Methods:

Synthesis of PbS CQDs: $0.25 \mathrm{mmol}$ of lead(II) acetate trihydrate (Aldrich, $99.999 \%, 94.375 \mathrm{mg}$ ), $0.5 \mathrm{mmol}$ of oleic acid (TCI, 99\%, 141mg), and $0.5 \mathrm{mmol}$ of 1-dodecanethiol (DT: Aldrich, $101 \mathrm{mg}$ ) were mixed in a 35 three-necked round bottomed flask (RBF). The mixed solution was degassed by stirring under vacuum at $100{ }^{\circ} \mathrm{C}$ for $2 \mathrm{~h}$. After cooling to $60{ }^{\circ} \mathrm{C}$, we added $4 \mathrm{ml}$ of diphenyl ether (Sigma-Aldrich, 99\%) and degassed it at $65{ }^{\circ} \mathrm{C}$ for $30 \mathrm{~min}$. The temperature was then increased to $155{ }^{\circ} \mathrm{C}$ under a $\mathrm{N}_{2}$ atmosphere, and $0.05 \mathrm{mmol}$ of tri-n-octylphosphine 40 (TOP: Stream, 97\%) and $0.05 \mathrm{mmol}$ of bis(trimethylsilyl)sulfide (TMS: Acros, 95\%) injection solutions were rapidly added to the three-necked $\mathrm{RBF}$ at $150{ }^{\circ} \mathrm{C}$. The reaction solution was kept at $120{ }^{\circ} \mathrm{C}$ for $30 \mathrm{~min}$ and then cooled to room temperature. The synthesized PbS CQDs (PbS-OADT) were purified by repeated precipitation for three times using 45 ethanol/isopropanol and re-dispersion in hexane. The reference $\mathrm{PbS}$ CQDs without the DT capping ligand (PbS-OA) were synthesized by the same procedure by using $1.25 \mathrm{mmol}$ of $\mathrm{OA}$ instead of $0.5 \mathrm{mmol}$ of $\mathrm{OA}$ and $0.5 \mathrm{mmol}$ of DT.

Device fabrication: A $1-\mu \mathrm{m}$-thick mesoporous $\mathrm{TiO}_{2}\left(\mathrm{mp}-\mathrm{TiO}_{2}\right.$ : average

50 particle size $=50 \mathrm{~nm}$, crystalline phase $=$ anatase $)$ photoanode film was prepared by screen printing on a dense blocking $\mathrm{TiO}_{2}$ layer $\left(\mathrm{bl}-\mathrm{TiO}_{2}: 50-\right.$ nm thick)/F-doped $\mathrm{SnO}_{2}$ (FTO, Pilkington, TEC15) glass substrate ${ }^{5 \mathrm{a}}$ and by subsequent calcination at $500{ }^{\circ} \mathrm{C}$ for $1 \mathrm{~h}$ in air. The interface of the $\mathrm{mp}-\mathrm{TiO}_{2}$ film was then treated using $20 \mathrm{mM}$ of aqueous $\mathrm{TiCl}_{4}$ solution at 55 room temperature for $12 \mathrm{~h}$ and sintered at $450{ }^{\circ} \mathrm{C}$ for $15 \mathrm{~min}$. To fabricate PbS CQD-SSCs, $100 \mu \mathrm{L}$ of the PbS CQDs (PbS-OA-DT) in a hexane/1,2 dichlorobenzene $(10 / 1 \mathrm{vol} / \mathrm{vol})$ solution $(15 \mathrm{mg} / 1 \mathrm{~mL})$ was spin-coated on a 3-mercaptopropionic acid (MPA: Aldrich) pre-treated $\mathrm{mp}-\mathrm{TiO}_{2}$ film at $2500 \mathrm{rpm}$ for $20 \mathrm{~s}$. The film was washed with chloroform during spin60 coating. In order to multiply stack the PbS CQDs, $250 \mu \mathrm{L}$ of a $1 \mathrm{wt} \%$ EDT (1,2-ethandithiol)/ethanol solution was spin-coated at $2500 \mathrm{rpm}$ for $20 \mathrm{~s}$, and the PbS CQD solution was then spin-coated at $2500 \mathrm{rpm}$ for 20 $\mathrm{s}$. We repeated spin-coating 15 times for the EDT and PbS CQDs. The
P3HT (poly-3-hexylthiophene) solution (Rieke Metals, >98\% 65 regioregular: $15 \mathrm{mg} / \mathrm{mL}$ in 1,2-dichlorobenzene) was then spin-coated on the PbS CQD-deposited film at $2500 \mathrm{rpm}$ for $1 \mathrm{~min}$. Poly(3-4ethylenedioxythiophene) doped with poly(4 stylenesulfonate) (PEDOT:PSS; Baytron AI 4083) solution/methanol (1/2 vol/vol) was spin-coated at $2000 \mathrm{rpm}$ for $30 \mathrm{~s}$, and a 60 -nm-thick Au counter electrode 70 was then deposited using thermal evaporation. To improve the interfacial contact between the PbS CQDs, the PbS CQD-SSCs were immersed in a $10 \mathrm{wt} \%$ EDT ethanolic solution for $15 \mathrm{~h}$. The EDT post-treated devices were then rinsed with ethanol and dried at $60{ }^{\circ} \mathrm{C}$ in an oven for $5 \mathrm{~min}$.

Device characterization: The current-voltage (I-V) characteristics of the 75 solar cell were measured using a solar simulator (Class A, 91195A; Newport) with a source meter (Keithley 2420) and a calibrated Sireference cell (certified by NREL) under 1 sun $\left(100 \mathrm{~mW} / \mathrm{cm}^{2}\right)$ illumination. The external quantum efficiency (EQE) was measured using a completely computerized home-designed system comprising a light 80 source (1000-W Xenon lamp, Newport, 69935) with a monochromator (Newport cornerstone 260) and a multimeter (Keithley 2002). The active area of the PbS CQD-SSCs for I-V characterization was fixed at $0.16 \mathrm{~cm}^{2}$, and the I-V curves were measured by placing a $0.096-\mathrm{cm}^{2}$ metal mask on the active area. Impedance measurement were carried out with a GSTAT8530 from Autolab, by applying 100 to $700 \mathrm{mV}$ in step of $50 \mathrm{mV}$ under light.

1 T. Bessho, S. M. Zakeeruddin, C. -Y. Yeh, E. W. -G Diau and M. Grätzel, Angew.Chem. 2010, 122, 6796.

2 A. J. Nozik, Chem. Phys. Lett., 2008, 457, 3.

903 (a) S. H. Im, Y. H. Lee and S. I. Seok, Electrochim. Acta, 2010, 55, 5665; (b) Y. H. Lee, S. H. Im, J. H. Rhee, J. -H. Lee and S. I. Seok, ACS Appl. Mater. Interfaces, 2010, 2, 1648; (c) Y. H. Lee, S. H. Im, J. -H. Lee and S. I. Seok, Electrochim. Acta 2011, 56, 2087; (d) S. H. Im, Y. H. Lee, S. I. Seok, S. W. Kim and S.-W. Kim, Langmuir 2010, 26, 18576.

4 (a) S. H. Im, J. A. Chang, S. W. Kim, S. -W. Kim and S. I. Seok, Org. Electron. 2010, 11, 696; (b) S. H. Im, H. -j. Kim, S. W. Kim, S. -W. Kim and S. I. Seok, Energy Environ. Sci. 2011, 4, 4188.

5 (a) J. A. Chang, J. H. Rhee, S. H. Im, Y. H. Lee, H. -J. Kim, S. I. 100 Seok, Md.K. Nazeeruddin and M. Grätzel, Nano Lett., 2010, 10, 2609; (b) S. H. Im, C. -S. Lim, J. A. Chang, Y. H. Lee, N. Maiti, H. -j. Kim, M. D. Nazeeruddin, M. Grätzel and S. I. Seok, Nano Lett., 2011, 11, 4789; (c) S. H. Im, H. -j. Kim, J. H. Rhee, C. -S. Lim and S. I. Seok, Energy Environ. Sci., 2011, 4, 2799; (d) C. -S. Lim, S. H. 105 Im, J. H. Rhee, Y. H. Lee, H. -j. Kim, N. Maiti, Y. Kang, J. A. Chang, M. D. Nazeeruddin, M. Grätzel and S. I. Seok, J. Mater. Chem., 2012, 22, 1107.

6 I. Moreels, K. Lambert, D. Smeets, D. D. Muynck, T. Nollet, J. C. Martins, F. Vanhaecke, A. Vantomme, C. Delerue, G. Allan and Z. Hens, ACS Nano, 2009, 3, 3023.

7 (a) J. Tang, X. Wang, L. Brzozowski, D. A. R. Barkhouse, R. Debnath, L. Levina and E. H. Sargent, Adv. Mater., 2010, 22, 1398; (b) J. Tang, L. Brzozowski, D. A. R. Barkhouse, X. Wang, R. Debnath, R. Wolowiec, E. Palmiano, L. Levina, A. G. Pattantyus-Abraham, D. 115 Jamakosmanovic and E. H. Sargent, ACS Nano, 2010, 4, 869.

8 (a) J. C. Love, L. A. Estroff, J. K. Kriebel, R. G. Nuzzo and G. M. Whitesides, Chem. Rev., 2005, 105, 1103; (b) M. A. Hines and G. D. Scholes, Adv. Mater., 2003, 15, 1844.

9 (a) D. H. Lee and R. A. Condrate, J. Mater. Sci., 1999, 34, 139; (b) P.

120 Thangadurai, S. Balaji and P. T. Manoharan, Nanotech., 2008, 19, 435708; (c) S. Chen and W. Liu, Mat. Chem. Phys., 2006, 98, 183.

10. (a) P. P. Boix, G. Larramona, A. Jacob, B. Delatouche, I. Mora-Seró and J. Bisquert, J. Phys. Chem. C 2012, 116, 1579; (b) P. P. Boix, Y. H. Lee, F. Fabregat-Santiago, S. H. Im, I. Mora-Seró, J. Bisquert and S. I. Seok, ACS Nano, 2012, 6, 873.

11. F. Fabregat-Santiago, G. Garcia-Belmonte, I. Mora-Seró and J. Bisquert, Phys. Chem. Chem. Phys. 2011, 13, 9083.

12. E. M. Barea, M. Shalom, S. Giménez, I. Hod, I. Mora-Seró, A. Zaban, J. Bisquert, J. Am. Chem. Soc. 2010, 132, 6834. 